www.jmscr.igmpublication.org

Index Copernicus Value: 79.54

ISSN (e)-2347-176x ISSN (p) 2455-0450

crossref DOI: https://dx.doi.org/10.18535/jmscr/v7i5.117

\title{
A Study of Epidemiological Correlates in Relation to Gestational Diabetes Mellitus
}

\author{
Dr Pratiksha Dwivedy ${ }^{1}$, Dr Kavita Baranwal ${ }^{2}$, Dr Harish Tiwari ${ }^{3}$, Dr D K Srivastava ${ }^{4}$ \\ ${ }^{1}$ Junior Resident, Deptt of Community Medicine, B R D Medical College, Gorakhpur, UP, India \\ ${ }^{2}$ Associate Professor, Deptt of Community Medicine, B R D Medical College, Gorakhpur, UP, India \\ ${ }^{3}$ Lecturer, Deptt of Community Medicine, B R D Medical College, Gorakhpur, UP, India \\ ${ }^{4}$ Professor, Deptt of Community Medicine, B R D Medical College, Gorakhpur, UP, India
}

\begin{abstract}
Objectives 1- To study the some of the ecological correlates of gestational diabetes mellitus among pregnant women attending Nehru Hospital, Gorakhpur.

Study Design: A cross-sectional study

Study Settings: Department of Obstetrics and Gynaecology, Nehru Hospital, Gorakhpur.

Study subject-All pregnant women of 24 weeks and above gestational age having OGTT report attending Nehru hospital during

Study Period: August 2017 to July 2018

Result: In the present study proportion of GDM done by using "WHO" criteria was $8.0 \%$.The proportion of GDM was higher among pregnant women who were in the age group of 20-30 years, literate, housewife by occupation, living in nuclear family, belong to social class IV+Class $V$ but the differences were not significant. In present study Family history of diabetes was significantly associated with GDM ( $p$-value 0.029). In relation to dietary factor, there was significant association in proportion of GDM seen, among those who were consuming less calories than the recommended calories.

Keywords: Gestational Diabetes Mellitus.
\end{abstract}

\section{Introduction}

India having the largest number of diabetic patients, India leads the world with earning the dubious distinction of being termed the "Diabetes Capital of the World". Pregnancy induces progressive changes in maternal carbohydrate metabolism. As pregnancy advances insulin resistance and diabetogenic stress due to placental hormones necessitate compensatory increase in insulin secretion. When this compensation is inadequate gestational diabetes develops.
'Gestational Diabetes Mellitus' [GDM] is defined as carbohydrate intolerance with onset or is first recognized during pregnancy. Women diagnosed to have GDM are at increased risk of future diabetes predominantly type $2 \mathrm{DM}$ as are their children ${ }^{1}$. Timely action taken now in screening all pregnant women for glucose intolerance, achieving euglycemia in them and ensuring adequate nutrition may prevent in all probability, the vicious cycle of transmitting glucose intolerance from one generation to 
another $^{2,3}$. In several studies, it was found that the prevalence of GDM has weak but significant relation with socio-economic status including education level, maternal age, dietary intake of pregnant mother and family history of diabetes mellitus. This association between GDM and epidemiological factors is not well recognized as a risk factor in developing countries, because of lesser number of studies done till now.

Gorakhpur is one of the major and largest district of Uttar Pradesh and is now the fastest developing city of the state. With the on growing development there is also a rise in the burden of non-communicable diseases in the area and it may be that GDM is one of the most important health care concern in this region and there is no data available regarding the prevalence of GDM in Gorakhpur, so this study is being conducted to know the prevalence and risk factors of GDM.

\section{Objectives}

To study the some of the ecological correlates of gestational diabetes mellitus among pregnant women attending Nehru Hospital, Gorakhpur.

\section{Material and Method}

The study was conducted in the outdoor setting in Department of Obstetrics and Gynaecology, Nehru Hospital, Gorakhpur. Patients from district Gorakhpur and nearby Gorakhpur such as Sant Kabir Nagar, Siddharthnagar, Basti, Deoria, Maharajganj and some districts of Bihar State being referred to BRD Medical College as this is the nearest tertiary care centre approachable. In view of the cross-sectional study design chosen, no sampling was done, as the intention was to cover all the pregnant women of gestational age $\geq 24$ weeks with their OGTT report. As per pilot study done it was found that on average 35-40 new pregnant women visits to the ANC OPD per day. Among them pregnant women with gestational age $\geq 24$ weeks was about $10-15$ in number and in them 8-12 ante-natal women had their OGTT reports at the time of consultation.
OPD visit day had been fixed Wednesday and Friday for data collection.

A total of 1161 participants were interviewed for their duration of pregnancy and history of diabetes. Among these 570 pregnant women were of gestational age $\geq 24$ weeks. The study aimed to cover the entire 570 pregnant women but 186 pregnant women were excluded as they did not have OGTT report at the time of data collection. However inspite of best efforts the coverage of pregnant women of gestational age $\geq 24$ weeks in the study was $67.4 \%$. However case was taken to ensure that total intake of study subject should not be less than 384. This sample size estimate is based on the assumption that approximate proportion of GDM is $50 \%$ as by this proportion largest sample size is calculated. Allowable error taken as $5 \%$ for present study.

Finally 384 pregnant women were included in present study. A pre designed \& pre-tested questionnaire was used for interviewing the study subjects. The interview questionnaire included information regarding the educational status in term of illiterate and literate, Occupation (Based on Udai Parikh's Classification), Type of Family, Income of the family (Revised BG Prasad's Classification 2018), Dietary habits, Adequate Calorie Intake (Consumption of 2400kcal per day is defined as adequate calorie intake), Adequate Protein Intake (Consumption of $1.1 \mathrm{gm} / \mathrm{kg}$ body weight per day is defined as adequate protein intake). Approximate calorific value of daily food intake was calculated on the basis of 24 hours recall method. ${ }^{4}$

Criteria for diagnosis of GDM: WHO diagnostic criteria of OGTT using 75 gms of anhydrous oral glucose was considered as the diagnostic tool to diagnose GDM. Recent consensus statement of Diabetes in Pregnancy Study Group of India calls for a uniform screening test with $75 \mathrm{~g}$ of post glucose test as the diagnosis enabling uniformity in diagnosis and comparative studies. ${ }^{5}$ OGTT report greater than $140 \mathrm{mg} / \mathrm{dl}$ were chosen as a case of GDM. 
Collected data through questionnaire was entered in the MS Excel spreadsheet and coded appropriately. Analysis was carried out using SPSS; all tests were performed at a 5\% level significance. Ethical Clearance had been taken from the ethical committee of B.R.D. Medical College.

\section{Result \& Discussion}

Table-1 Age-wise distribution of GDM \& Non GDM subjects

\begin{tabular}{|c|c|c|c|c|c|c|}
\hline \multirow{2}{*}{ Age Group } & \multicolumn{2}{|c|}{ GDM } & \multicolumn{2}{|c|}{ Non GDM } & \multirow{2}{*}{ chi sq } & \multirow{2}{*}{ p-value } \\
\hline & No. & $\%$ & No. & $\%$ & & \\
\hline$<20$ years & 1 & 3.3 & 5 & 1.4 & \multirow{4}{*}{4.53} & \multirow{4}{*}{0.104} \\
\hline $20-30$ years & 23 & 76.7 & 317 & 89.5 & & \\
\hline$>30$ years & 6 & 20 & 32 & 9.1 & & \\
\hline Total & 30 & 100 & 354 & 100 & & \\
\hline
\end{tabular}

Table-1shows the relation of GDM and non-GDM subjects in relation to their age-group. Among the GDM group majority $(76.7 \%)$ of the cases were in the age group of $20-30$ years and $89.5 \%$ among non-GDM belonged to the same age group as in GDM. No significant association seen between age distribution \& GDM. (p-value $=0.104$ ). In study conducted by Rajput et al, (2014) majority of subjects (68.8\%) belonged to age group 20-24 years. ${ }^{5}$ In another study by Kalra et al (2013) the mean age of the patient was $25.33+3.17$ years and Age $>25$ years were significantly associated with GDM group. ${ }^{6}$

Table-2 Association of Educational Status with GDM

\begin{tabular}{|l|c|c|c|c|c|c|}
\hline \multirow{2}{*}{ Education } & \multicolumn{2}{|c|}{ GDM } & \multicolumn{2}{|c|}{ Non GDM } & \multirow{2}{*}{ chi sq } & \multirow{2}{*}{ p-value } \\
\cline { 2 - 5 } & No. & $\mathbf{\%}$ & No. & $\mathbf{\%}$ & & \\
\hline Illiterate & 10 & 33.3 & 179 & 50.5 & \multirow{3}{*}{3.29} & \multirow{2}{*}{0.070} \\
\hline Literate & 20 & 66.7 & 175 & 49.5 & & \\
\hline Total & 30 & 100 & 354 & 100 & & \\
\hline
\end{tabular}

Table-2 shows the distribution of GDM \&Non GDM subjects in relation to their educational status. Among GDM group, majority of the patients were literate while in Non-GDM group proportion of literate as well as illiterate was almost similar (ie; $50.5 \%$ \& $49.5 \%$ ). The association of GDM with educational status was found to be non-significant ( $p$-value $=0.070$ ). Similarly in a study by Verma et al, (2008) reported that there was no significant relationship between education \& prevalence of $\mathrm{GDM}^{7}$ In accordance with the Rajput et al, (2013) reported that GDM rate increased with increasing educational qualification of the participants and it was found statistically significant. ${ }^{8}$ Another study by Raja et al, (2013) observed preponderance of illiterate female $(52.9 \%)$ and there was no significant association between GDM and literacy $(\mathrm{p}>0.05){ }^{9}$

Table -3 Association of occupational status with GDM

\begin{tabular}{|c|c|c|c|c|c|c|}
\hline \multirow{2}{*}{ Occupation } & \multicolumn{2}{|c|}{ GDM } & \multicolumn{2}{|c|}{ Non GDM } & \multirow{2}{*}{ chi sq } & \multirow{2}{*}{$\begin{array}{c}\text { p- } \\
\text { value }\end{array}$} \\
\hline & No. & $\%$ & No. & $\%$ & & \\
\hline Labourer & 0 & 0 & 2 & 0.5 & \multirow{6}{*}{4.82} & \multirow{6}{*}{0.307} \\
\hline Caste Occupation & 3 & 10 & 11 & 3.2 & & \\
\hline Cultivation & 0 & 0 & 8 & 2.2 & & \\
\hline Service (Office Job) & 0 & 0 & 4 & 1.1 & & \\
\hline Housewife (none) & 27 & 90 & 329 & 93 & & \\
\hline Total & 30 & 100 & 354 & 100 & & \\
\hline
\end{tabular}


Table-3 shows the distribution of GDM \&Non GDM subjects in relation to their occupational status. In the present study majority of the studied participants were housewives in both GDM and non- GDM groups i.e; $90 \%$ and $93 \%$ respectively. Maximum prevalence of GDM (90\%) was found in women doing household works followed by those engaged in caste occupation (10\%), and no case of GDM was found from cultivation, labourer and office job class $(0 \%)$. No significant association was found between type of occupation and GDM, $(\mathrm{P}$ value $=0.307)$.

Similar finding were present in study by Rajput $\boldsymbol{e t}$ al, (2014) majority (78.4\%) of the participants were housewives. ${ }^{5}$ Similarly Keshavarz et al, (2005) also found no association between GDM and occupation. ${ }^{10}$ In contrary to our study, Verma et al, (2008) found occupation as significant variable. $^{7}$

Table-4 Association of type of family with GDM

\begin{tabular}{|c|c|c|c|c|c|c|}
\hline \multirow{2}{*}{ Type of family } & \multicolumn{2}{|c|}{ GDM } & \multicolumn{2}{|c|}{ Non GDM } & \multirow{2}{*}{ chi sq } & \multirow{2}{*}{$\begin{array}{c}\text { p- } \\
\text { value }\end{array}$} \\
\hline & No. & $\%$ & No. & $\%$ & & \\
\hline Nuclear & 19 & 63.3 & 179 & 50.5 & \multirow{3}{*}{1.81} & \multirow{3}{*}{0.179} \\
\hline Joint & 11 & 36.7 & 175 & 49.5 & & \\
\hline Total & 30 & 100 & 354 & 100 & & \\
\hline
\end{tabular}

Table-4 shows the distribution of GDM \&Non GDM subjects in relation to their type of family In present study $63.3 \%$ of study participants diagnosed with GDM belonged to nuclear family type and 36.7 to the joint type. Amongst the Non-
GDM group proportion was almost equal in the respective types ie; $50.5 \& 49.5$ There was no significant association found between type of family and GDM (P value=0.179)

Table- 5 Association of Socio-economic status with GDM

\begin{tabular}{|c|c|c|c|c|c|c|}
\hline \multirow{2}{*}{ SES } & \multicolumn{2}{|c|}{ GDM } & \multicolumn{2}{|c|}{ Non GDM } & \multirow{2}{*}{ chi sq } & \multirow{2}{*}{ p-value } \\
\hline & No. & $\%$ & No. & $\%$ & & \\
\hline Class I + Class II & 8 & 26.6 & 75 & 21.1 & \multirow{4}{*}{0.56} & \multirow{4}{*}{0.755} \\
\hline Class III & 11 & 36.7 & 131 & 37.0 & & \\
\hline Class IV+ Class V & 11 & 36.7 & 148 & 41.9 & & \\
\hline Total & 30 & 100 & 354 & 100 & & \\
\hline
\end{tabular}

-Class I and Class II was taken as 1 parameter as only one participant belonged to class -I similarly class- IV and Class -V was taken as one parameter as there were only three participants from classIV

Table-5 shows the distribution of GDM \&Non GDM subjects in relation to their socio-economic status. In the GDM group the proportion was equal in the middle class as well as in low middle class +lower class ie;36.7\% while 26.6 of the studied subjects belonged to the upper middle + upper class. Amongst the Non-GDM proportion was higher in women belonging to lower middle+ lower class $41.9 \%$ followed by $37 \%$ in middle class with the least number of cases in upper class+ upper middle class $(21.1 \%)$. There was no significant association found between socioeconomic status and GDM (P value $=0.755)$. Similarly, Verma et al (2008), revealed no significant association between socioeconomic status and GDM.

Table-6 Association of family history of diabetes \& GDM

\begin{tabular}{|l|c|c|c|c|c|c|}
\hline \multirow{2}{*}{$\begin{array}{l}\text { Family History } \\
\text { of GDM }\end{array}$} & \multicolumn{2}{|c|}{ GDM } & \multicolumn{2}{|c|}{ Non GDM } & \multirow{2}{*}{ chi sq } & \multirow{2}{*}{ p-value } \\
\cline { 2 - 5 } & No. & $\boldsymbol{\%}$ & No. & $\boldsymbol{\%}$ & & \\
\hline Yes & 10 & 33 & 61 & 17 & \multirow{2}{*}{4.758} & \multirow{2}{*}{0.029} \\
\hline No & 20 & 67 & 293 & 83 & \\
\hline Total & 30 & 100 & 354 & 100 & & \\
\hline
\end{tabular}


Table- 6 shows the distribution of study subjects on the basis of family history of diabetes. In the present study, $33 \%$ subjects who had family history of diabetes belong to GDM group and $17 \%$ having family history of diabetes belong to Non GDM group. In present study Family history of diabetes was significantly associated with GDM (p-value $=0.029)$.In the present study, among the participants diagnosed with GDM 33\% and $17 \%$ of participants with non-GDM had family history of diabetes mellitus. Family history of diabetes mellitus was significantly associated with GDM ( $\mathrm{p}$-value $=0.029$ ).
In a tertiary care hospital study, by Rajput et al (2013), reported significant association between family history of Diabetes and GDM. ${ }^{8}$ In another community based study, Seshiah et al (2008), reported that family history of diabetes was an independent predictor of GDM (OR: 1.58, 95\% CI: 1.39-1.79). ${ }^{11}$ Similarly in a study by, Bhat et al (2010), in case control study revealed a significant relationship between GDM and family history. ${ }^{12}$

Table-7 Association of Dietary intake with GDM

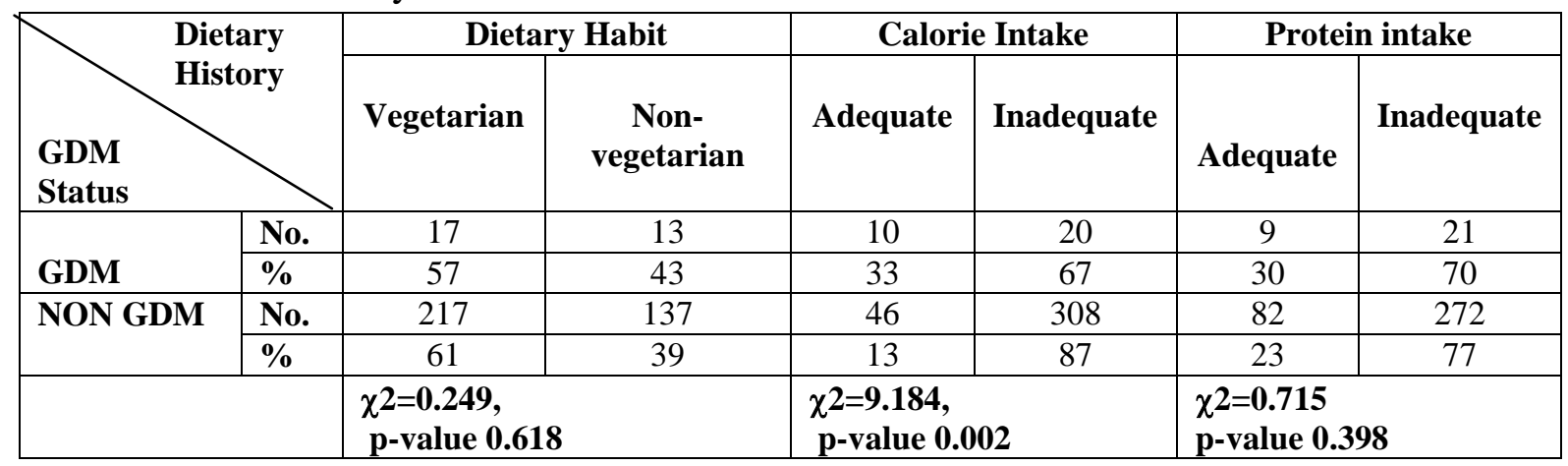

Table-7 shows the distribution of studied subjects on the basis of their dietary Habit, calorie intake and protein intake. among the GDM group 57\% of the subjects were vegetarian and $13 \%$ were non vegetarian while in the non-GDM group proportion were $61 \quad \& 39 \%$ respectively. Distribution of study subjects on the basis of their caloric intake showed only $33 \%$ of the diagnosed GDM women were having adequate calorie intake and only $13 \%$ among Non-GDM were consuming adequate calories. On the basis of their protein intake, among the GDM group only 30\% of the women were having adequate protein intake while only $23 \%$ among Non-GDM were taking adequate protein intake. There was a significant association between calorie-intake and GDM. In a study conducted by M.V. Jali et al (2011), found that non-vegetarian pregnant women are more susceptible to develop abnormal glucose tolerance. $^{13}$

In particular, Saldana et al (2004), showed that higher intake of fat and lower intake of carbohydrates may be associated with increased risk of GDM and impaired glucose tolerance (IGT). ${ }^{15}$

\section{Conclusion}

The present study was undertaken in BRD Medical College, Gorakhpur to identify the epidemiological correlates of GDM. In this study Proportion of GDM cases was $8.0 \%$. Majority of study participants diagnosed with GDM (76.7\%) \& non-GDM (89.5\%) belonged to age group 2030 years. Though the proportion of GDM were high among literate, housewives, nuclear families, belonging to social class IV $+\mathrm{V}$ (lower- middle $\&$ lower class), but there was no significant association seen. Family history of diabetes mellitus was significantly associated with GDM ( $\mathrm{p}$-value $=0.029$ ). Study participants diagnosed with GDM (33\%) and among non-GDM (13\%) had adequate calorie-intake. There was a significant association between GDM and caloricintake seen. 


\section{Recommendation}

Pregnancy is a time when women may become more aware of their health and make positive lifestyle changes. During pregnancy, women frequently engage with the health care system, especially if they develop any complication. Following suggestions are recommended for decreasing the prevalence of gestational diabetes and preventing to develop overt diabetes in mothers as well their children.

The target population should be encouraged for regular screening for diabetes in future. Attention to physical activity and dietary habits during pregnancy and afterwards needs to be a serious and routine component of antenatal care, especially for women who are diagnosed with GDM, for GDM management and Type 2 diabetes prevention. Research focus should be on primary prevention by health education/ behaviour change communication in primary and secondary care settings.

\section{References}

1. International Diabetes Federation. A summary of the figures and key findings. The IDF Diabetes Atlas.6th edition. Brussels, Belgium: International Diabetes Federation; 2013.

2. World Health Organization. Definition, diagnosis and classification of diabetes mellitus and its complications. Report of a WHO consultation. Part 1: Diagnosis and classification of diabetes mellitus. Geneva: WHO; 1999 [cited 2009 Aug 18]. WHO/NCD/NCS/99.

3. Pickup JC, Williams G. Textbook of diabetes. 3rd edition. London: Wiley Blackwell; 2003.

4. Park K. Park's Text book of preventive and social medicine.23rd Edition. Jabalpur:M/s Banarsidas Bhanot;2015:608-629.
5. Rajput M, BairwaM ,RaputR.Prevalance of GDM in rural Haryana:A community-based study. Indain $\mathbf{J}$ of Endocrinology and Metabolism

2014;18(3):14.98.249.50, available at http:www.ijem.in assesed on July 10,2014.

6. E.Karla P, Kachhwaha CP, Singh HV. Prevalance of GDM and its outcome in western Rajasthan. Indian $\mathbf{J}$ Endocrinology and Metabolism July 2013;17;4.

7. Verma AK, Singh B, Mengi V. Gestational diabetes in rural women of Jammu. Indian $\mathrm{J}$ Community Med 2008;33(1);54-5.

8. Rajput R, Yadav Y, Nanda S, Rajput M. Prevalance of GDM and associatioted risk factors at a tertiary care hospital in Haryana. Indian j MedRes 2013;137:728-733.

9. Raja MW, Baba TA, Hanga AJ, Bilquees S, Rasheed S, HaqIU.Prevalence Of GDM In An Urban Block of Kashmir Valley(North India). International $\mathrm{j}$ Med Science and Public Health;2014;3;2.

10. Keshavarz M, Cheung NW, Babaee GR, Moghadam HK, Ajami ME, Shariati M. Gestational diabetes in Iran: incidence, risk factors and pregnancy outcomes. Diabetes Res clinpract 2005;69:279-86.

11. Seshiah V, Balaji V, Balaji MS, Paneerselvam A, Arthi T, Thamizharasi M. Prevalence of GDM in South India - A community based study. J Assoc Physicians India 2008;56:329-33.

12. Bhat M, Ramesha K N, Sarma SP, Menon S, Sowmini CV, Kumar SG. Determinants of GDM: A case control study in a district tertiary care hospital in south India. Int $\mathbf{J}$ Diabetes DevCtries 2010;30(2):91-96.

13. Jali M.V, Desai B R ,Gowda S, Kambar, Jali S.M. A hospital based study of prevalence of GDM in an urban population of India. Europ Rev Med Pharma Sci. 2011;15: 1306-1310. 